\title{
BRAF V600E and decreased NIS and TPO expression are associated with aggressiveness of a subgroup of papillary thyroid microcarcinoma
}

\author{
André Uchimura Bastos, Gisele Oler, Bruno Heidi Nakano Nozima, \\ Raquel Ajub Moysés ${ }^{1}$ and Janete Maria Cerutti
}

Laboratório as Bases Genéticas dos Tumores da Tiroide, Disciplina de Genética, Departamento de Morfologia e Genética, Universidade Federal de São Paulo (UNIFESP), Rua Pedro de Toledo, $669-11^{\circ}$ andar, 04039-032 São Paulo, São Paulo, Brazil and ${ }^{1}$ Disciplina de Cirurgia de Cabeça e Pescoço, Departamento de Cirurgia, Universidade de São Paulo, São Paulo, São Paulo, Brazil

\author{
Correspondence \\ should be addressed \\ to J M Cerutti \\ Email \\ j.cerutti@unifesp.br
}

\section{Abstract}

Background: Thyroid cancer incidence has dramatically increased worldwide over the last two decades. The rise is mostly due to an increased detection of small papillary thyroid carcinomas (PTCs) $(\leq 20 \mathrm{~mm})$, predominantly microPTC $(\leq 10 \mathrm{~mm})$. Although small tumors generally have an excellent outcome, a considerable percentage may have a more aggressive disease and worse prognosis. The clinical challenge is to preoperatively identify those tumors that are more likely to recur.

Aim: To improve risk stratification and patient management, we sought to determine the prognostic value of BRAF V600E, NRAS or RETIPTC mutations in patients with PTC measuring $<20 \mathrm{~mm}$, mainly microPTC.

Methods: The prevalence of RETIPTC fusion genes was examined by quantitative RT-PCR. BRAF V600E and NRAS Q61 mutations were determined by PCR sequencing. To further elucidate why some small PTC are less responsive to radioactive iodine treatment therapy, we explored if these genetic alterations may modulate the expression of iodine metabolism genes (NIS,TPO,TG, TSHR and PDS) and correlated with clinico-pathological findings that are predictors of recurrence.

Results: This study shows that tumors measuring $\leq 20 \mathrm{~mm}$ exhibited higher prevalence of BRAF V600E mutation, which correlated with aggressive histopathological parameters, higher risk of recurrence, and lower expression of NIS and TPO. Although this correlation was not found when microPTC were evaluated, we show that tumors measuring 7-10 mm, which were positive for BRAF mutation, presented more aggressive features and lower expression of NIS and TPO.

Conclusion: We believe that our findings will help to decide the realistic usefulness of BRAF V600E mutation as a preoperative marker of poor prognosis in small PTC, primarily in microPTC.

\section{Introduction}

Thyroid cancer is the fastest increasing cancer worldwide. The increase is predominantly due to an increased detection of small tumors, predominantly from papillary subtype (papillary thyroid carcinoma (PTC)). Eighty-seven percent of the cases consisted of PTC measuring $20 \mathrm{~mm}$ or less, and nearly $50 \%$ of the increase consisted of PTC measuring $10 \mathrm{~mm}$ or less in size (papillary thyroid microcarcinoma (microPTC)) $(1,2,3)$.
Once a nodule has been identified, the first decision is whether fine-needle aspiration (FNA) should be performed to exclude malignancy. The Guidelines of the American Thyroid Association (4) recommend that only nodules $>10 \mathrm{~mm}$ should undergo FNA and that nodules measuring $\leq 10 \mathrm{~mm}$ should be biopsied on the basis of suspicious ultrasonographic findings or if there is family history of thyroid cancer or history of radiation exposure.

Published by Bioscientifica Ltd 
However, there is still no consensus in the literature on whether a nodule of $10 \mathrm{~mm}$ or smaller should be selected for biopsy and if it should undergo follow-up. The controversy is mainly related to the fact that, despite the excellent clinical outcome of patients with microPTC, which are commonly seen as being low-risk tumors, a significant number of cases were associated with extracapsular invasion, lymph node metastases at presentation, tumor recurrence, distant metastases, advanced tumor stage and even disease-specific mortality $(5,6,7)$. Therefore, it is of clinical importance to identify biomarkers that would help to risk-stratify and appropriately manage patients with small thyroid nodules.

PTCs commonly have genetic alterations that lead to the activation of the MAPK pathway. BRAF V600E mutation is the most common event found in PTC, followed by RET/PTC rearrangements. Although more than 13 RET/PTC rearrangements have been described, RET/PTC1 and RET/PTC3 are the most prevalent isoforms (8). Finally, activating mutation of $R A S$ genes (NRAS, KRAS and HRAS) has also been described in a small subset of PTC. It has been observed that these driver alterations that affect the same pathway occur in a mutually exclusive pattern and are associated with distinct clinical, microscopic and biological features of PTC $(9,10,11,12)$. BRAF V600E mutation has been associated with more aggressive features such as extrathyroidal extension, presence of lymph node metastases, advanced tumor stages, higher risk of recurrence and disease-specific mortality (10, 11, 12, 13). RET/PTC and RAS were less frequently associated with an aggressive phenotype.

Within this perspective, several studies have assessed the clinical prognostic use of these genetic alterations in microPTC. Few studies correlated the presence of BRAF V600E mutation with a more aggressive phenotype $(7,11$, $12,14,15,16,17,18,19,20)$. Although the prevalence of RET/PTC rearrangement is higher in microPTC than in larger tumors, its role as a prognostic indicator is still unclear (21).

The primary goal of this study was to evaluate if the most frequent genetic alterations along MAPK pathway found in PTC may help to recognize those small PTC with a more aggressive phenotype, primarily microPTC. The current treatment for PTC includes thyroidectomy, TSH suppression and adjuvant therapy with radioactive iodine treatment (RAI), PTC recurrence and death essentially occurs in tumors that have lost radioiodine avidity. Loss of expression of thyroid-specific proteins involved in the iodine uptake, concentration and organification lead to the loss of radioiodine avidity and, consequently, failure of radioiodine therapy $(22,23,24,25)$.
Recently, in a landmark article by the Cancer Genome Atlas Research network (TCGA), the authors used comprehensive multiplatform analysis to characterize the genomic landscape of PTC. A molecular classification of PTCs, based on combined analysis of genomic variants, transcriptoma, proteome and methyloma with clinicopathological information of 496 PTC, identified two major clusters defined as BRAF V600E-like and RAS-like. The BRAF V600E-like pattern comprise mainly less differentiated variants of PTC enriched for classical and tall variants, showed over-activation of the MAPK pathway and reduced expression of proteins involved in iodine uptake and metabolism. RAS-like patterns were enriched with more differentiated variants of PTC and lower activation of MAPK signaling than BRAF V600E-like PTCs (26).

As a percentage of microPTC do not respond to standard therapy, tumor size was not an independent variable of the TCGA dataset and also is not a feature available for comparisons (www.genome-cancer.ucsc. edu), it seems rational to investigate the expression of genes associated with iodine uptake and organification in these tumors and to explore whether the BRAF and $R A S$ mutations and RET/PTC fusion genes downregulate the expression of genes involved in iodine metabolism, as it has been suggested for larger PTC. Therefore, we correlated the mutational status with the expression of sodiumiodine symporter (NIS), thyroglobulin $(T G)$, thyroperoxidase (TPO), thyrotropin receptor (TSHR) and pendrin (PDS) and clinico-pathological features.

As far as we know, this is the first study that investigates the prognostic impact of BRAF, RAS and RET/PTC in the same series of microPTC and addresses the specific question of how these events affect the expression of key genes associated with iodine metabolism.

\section{Methods}

\section{Tissue samples}

The series consists of 118 PTCs and seven normal adjacent thyroid tissues obtained from patients who underwent thyroid surgery at Hospital São Paulo, UNIFESP and Hospital das Clínicas, Faculdade de Medicina da Universidade de São Paulo. The specimens were frozen in liquid nitrogen immediately after surgical resection and stored at $-80{ }^{\circ} \mathrm{C}$ until use. Final histological classification was obtained from paraffin-embedded sections. The clinical and pathological features such as the age at onset, gender, tumor size, histological variant, 
multifocality, extrathyroidal invasion and presence of lymph node metastasis were evaluated. Additionally, all patients were grouped into three risk categories at the time of initial treatment (27): i) Very low risk: unifocal T1 $(\leq 10 \mathrm{~mm})$ with no extension beyond the thyroid and no lymph node metastases (T1aNOM0). ii) Low risk: T1bNOM0 (tumor $>10 \mathrm{~mm}$ and $<20 \mathrm{~mm}$ ), T2NOMO or multifocal T1NOM0. iii) High risk: any $\mathrm{T} 3$ and T4 or any T, N1 or any M1. Follow-up protocol included neck ultrasound (US), serum TG (sTg), anti-TG antibodies $(\mathrm{TgAb})$ and whole body scan. Patients were considered with 'no evidence of disease' when they presented negative neck US and undetectable sTg (below $1 \mathrm{ng} / \mathrm{ml}$ ) and $\mathrm{TgAb}$ levels (bellow $40 \mathrm{IU} / \mathrm{ml}$ ). Informed consent was obtained from all subjects involved in this study. The study was conducted under the approval of the Review Boards and Research Ethical Committees of the affiliated institutions.

\section{NRAS Q61 and BRAF V600E mutation analysis}

According to the catalogue of somatic mutations in cancer (http://sanger.ac.uk/cosmic), different types of cancer appear to be coupled to mutation of a particular $R A S$ isoform (NRAS, KRAS and HRAS). NRAS is the most frequently mutated $R A S$ isoform in PTC, with the highest rates of mutation found at Q61 (exon 2). NRAS was also reported as the second most common mutation found in PTC by the TCGA project (26). The Q61 mutation in the exon 2 of NRAS gene was investigated by PCR. PCR products were resolved by electrophoresis, purified and submitted to direct sequencing as described (13). The samples were sequenced at least twice and in both directions. BRAF V600E mutation was previously investigated in this series of PTC (28). The PCR primers and conditions are summarized in Supplementary Table 1, see section on supplementary data given at the end of this article.

\section{Detection of RET/PTC fusion genes by RT-PCR}

All tumors were screened for RET/PTC1, RET/PTC2 and RET/PTC3 rearrangements by RT-PCR, as previously described, with few modifications (29). Briefly, $1 \mu \mathrm{l}$ of cDNA synthetized as described (30) was used in $12 \mu \mathrm{l}$ reactions containing SYBR Green PCR Master Mix (PE Applied Biosystems) and predesigned primers that span the known breakpoints specific for each of the RET/PTC transcripts (29) or internal control (RPS8). PCR reaction was performed in triplicate and the threshold cycle $(\mathrm{Ct})$ was obtained using Applied Biosystem Software. Postamplification fluorescent melting curve analysis was performed. The PCR products were analyzed by electrophoresis on a $2 \%$ agarose gel and visualized on a Bio-Rad Gel Doc EZ system (Bio-Rad). cDNA generated from PCCL3 cells transiently transfected with plasmids encoding RET/PTC2 or RET/PTC3 isoforms or TPC1 cell line (positive for RET/PTC1) were used as positive controls. The samples were considered positive when at least two replicates had amplification curves that crossed the threshold before cycle 35, the melt curve aligned with the positive control, and the gel analysis revealed a band of the expected product size. To confirm the identity of the amplified products, randomly selected positive samples were sequenced using the BigDye Terminator Cycle Sequencing kit (PE Applied Biosystems).

In addition, the presence of $R E T / P T C$ rearrangements was confirmed by expression analysis of both extracellular (EC) domain and tyrosine kinase (TK) domain of RET, as previously described $(31,32,33,34,35,36)$. Two pair of primers were designed to amplify the region encoding the EC domain (exons 6 and 7) and TK domain of RET (exons 16 and 18). An aliquot of cDNA was used in $12 \mu \mathrm{l}$ PCR reaction containing SYBR Green PCR Master Mix (PE Applied Biosystems) and $2.5 \mathrm{pmol}$ of each primer. qPCR reactions were performed in triplicate and the $C t$ was averaged (s.D. <1.0). Samples with balanced ratio (i.e. the expression of the EC and the TK domain was $~ 1: 1$ ) were considered negative for RET fusion transcripts. Samples with unbalanced expression (i.e. the expression of TK domain was higher than the expression of the EC domain) were considered positive for RET/PTC fusion transcripts. The PCR primers and conditions are summarized in Supplementary Table 1.

\section{Expression of iodine metabolism genes using quantitative RT-PCR}

cDNA, synthesized as in the preceding, was used in a $12 \mu \mathrm{l}$ PCR reaction containing SYBR Green PCR Master Mix (PE Applied Biosystems) and $2.5 \mathrm{pmol}$ of each primer for the target genes (NIS, TG, TPO, TSHR, PDS) or internal control (RPS8). The PCR reactions were performed in triplicate, and the $C t$ was obtained using Applied Biosystem software and averaged (s.D. <1.0). The relative expression (RE) was calculated according to the comparative $\Delta \Delta C$ t method. Normal thyroid samples were used as the control group. The PCR primers and conditions are summarized in Supplementary Table 1. 


\section{Statistical analyses}

Raw data from qRT-PCR was in-transformed before submitted to statistics. The association between mutational status and clinico-pathological features was determined using Fisher's exact test. The association between tumor size and clinico-pathological features was determined using Student's $t$-test. The comparison between the expression of the EC and the TK domains of RET were performed using Student's $t$-test. The association between mutational status and gene expression was performed using the one-way ANOVA test followed by Bonferroni's post-hoc test. Statistical analyses were performed using STATA Software (StataCorp, College Station, TX, USA). The results with $P<0.05$ were considered to be statistically significant.

\section{Results}

\section{Mutational analysis of PTC}

We initially investigated RET/PTC rearrangements by RT-PCR. For the direct detection of RET/PTC1, RET/PTC2 and RET/PTC3, RT-PCR was performed with forward primer mapping on the respective fusion partners and reverse primer on the RET gene. Overall, RET/PTC fusion transcripts were identified in $27 \%$ (32 out of 118) of PTC. RET/PTC1 was detected in 9\% $(n=11), R E T / P T C 2$ in $10 \%$ $(n=12)$ and RET/PTC3 in 5\% $(n=6)$. Multiple RET/PTC rearrangements were found in $3 \%(n=3)$, being two cases of RET/PTC1 associated with RET/PTC2 and one case of RET/PTC1 associated with RET/PTC3 (Supplementary Table 2 , see section on supplementary data given at the end of this article).

Furthermore, to confirm the presence of RET fusion transcripts, the expression both EC and TK domains of RET were evaluated in samples positive for RET/PTC1, RET/PTC2 and RET/PTC3 isoforms $(n=25)$ and samples negative for RET/PTC isoforms $(n=25)$. Comparison of $C \mathrm{t}$ value showed balanced expression of exons 6-7 (encoding the EC domain) and 16-18 (encoding the TK domain) of RET in all cases negative for RET/PTC fusion transcripts. The expression of the TK was significantly higher than expression of the EC domain in all cases considered positive in the direct detection of RET/PTC1, RET/PTC2 or $R E T / P T C 3$ assay $(P<0.001$; Fig. 1$)$. Representative $C t$ plots of a sample without RET/PTC fusion transcripts and a sample with multiple RET/PTC fusion transcripts are shown (Fig. 1). Random selected cases that were positive for RET/PTC rearrangements, according to the criteria

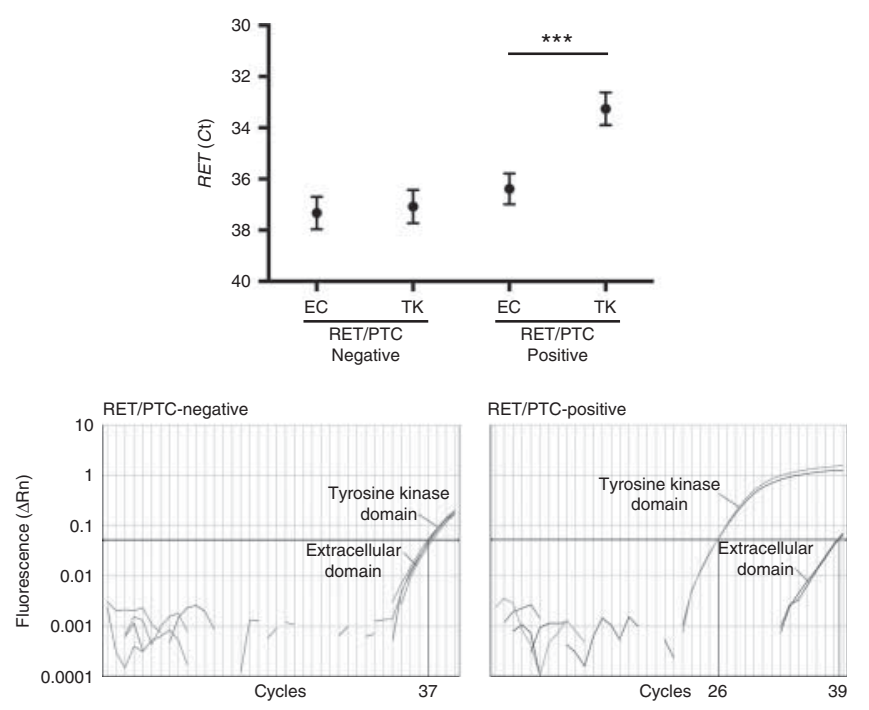

Figure 1

Analysis of RET unbalanced expression in PTC samples. The figure above shows the mean $C t$ value of exons 6-7 (encoding EC domain) and exons 16-18 (encoding TK domain) of RET in RET/PTC-negative $(n=25)$ and RET/PTC-positive $(n=25)$ samples according to qPCR analysis. RET/PTC-negative samples have a comparable $C t$ value for both domains (ratio $1: 1 ; 37.3 \pm 0.6$ vs $37.1 \pm 0.6)$ although RET/PTC-positive samples have a higher expression of TK domain compared to EC-domain of RET (36.4 \pm 0.6 vs $33.3 \pm 0.6$ ). The panel below shows representative Ct plots from qPCR of exons 6-7 and exons 16-18 of a sample without RET fusion oncogene (left) and a sample with multiple RET fusions (right). *** $P<0.001$.

described in Methods section, were also positive by sequencing data.

NRAS mutation was found in $9 \%(n=11)$ of PTCs. The Q61R substitution was found in 10/11 PTC, whereas the Q61K substitution was identified in 1/11 case. BRAF V600E mutations were found in $48 \%(n=57)$ of PTC, as previously described (13) (Supplementary Table 2).

Additionally, concomitant mutations were found in 17\% $(n=20)$ of PTC. Fifteen cases carried both RET/PTC and BRAF V600E mutation and five cases had both RET/PTC and NRAS Q61R (Fig. 2A). RET/PTC2 was the most prevalent isoform found in association with $B R A F$ or NRAS (Supplementary Table 2).

In summary, $32 \%$ of PTCs were negative for mutations. BRAF V600E only was detected in 36\% of PTC cases, RET/PTC only in $10 \%$, NRAS only in $5 \%$ and concomitant mutations in $17 \%$ (Fig. 2A). Importantly, although in the majority of studies, BRAF V600E, RET/PTC 

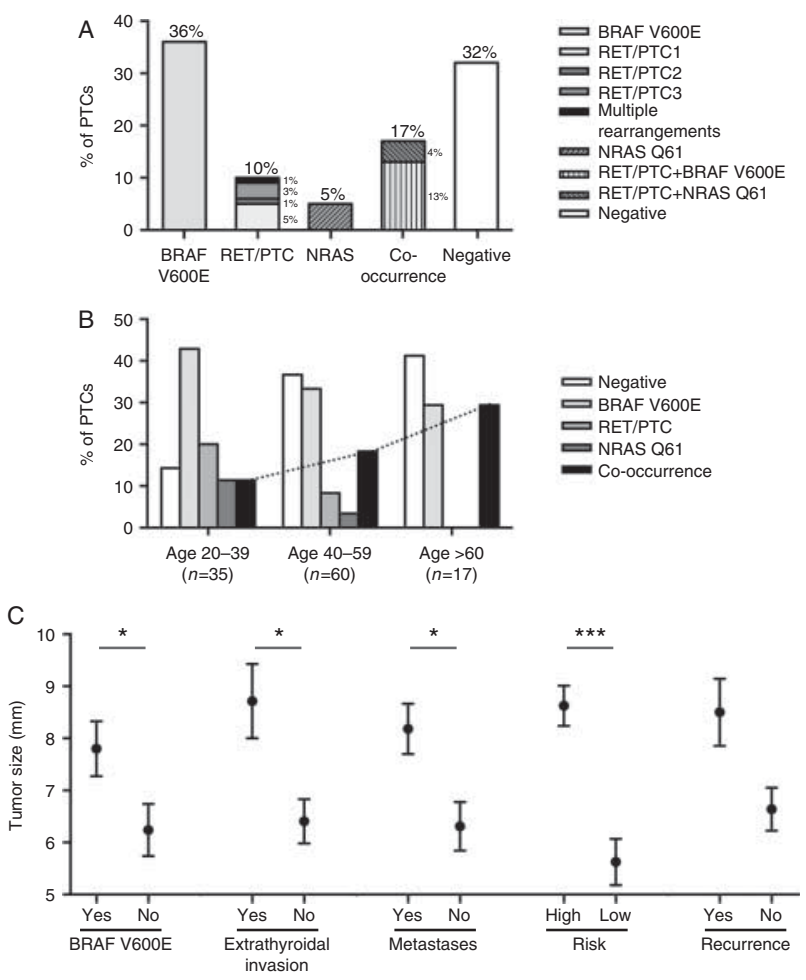

\section{Figure 2}

Mutational status and clinico-pathological parameters of papillary thyroid carcinomas. (A) Prevalence of BRAF, RET/PTC and NRAS in PTC. (B) Samples were further classified into threeage groups. RETIPTC or NRAS alone are more prevalent in younger patients, whereas the prevalence of concomitant mutations increases with age (C) Tumors measuring $\leq 10 \mathrm{~mm}$ were further evaluated according to tumor size and clinicopathological parameters associated with recurrence and death and presence of BRAF V600E. MicroPTC measuring $\geq 7 \mathrm{~mm}$ had more frequent extrathyroidal invasion $(P=0.023)$, presence of lymph node metastasis $(P=0.028)$, high risk $(P<0.001)$ and BRAF V600E mutation ( $P=0.049)$, compared to microPTC measuring $<7 \mathrm{~mm}$. * $P<0.05$ and $* * * P<0.001$.

and RAS exhibited a mutually exclusive pattern, concomitant mutations in these genes were previously reported in PTC (Table 1).

\section{Association of mutational status with clinico-pathological features}

In general, mutations along MAPK were associated with pathological features indicative of more aggressive behavior such as larger tumor size $(P=0.021)$, presence of lymph node metastases at diagnosis $(P=0.048)$ and high risk $(P<0.001)$, suggesting that mutations along MAPK pathway may have a direct effect on the biological behavior of PTC. However, when each mutation was considered as an independent variant, only BRAF V600E was significantly associated with classic variant of PTC $(P<0.001)$, larger tumor size $(P=0.040)$, presence of lymph node metastases at diagnosis $(P=0.002)$ and high risk $(P=0.005)$ (Table 2$)$. These findings suggest that the association with clinical and pathological features representative of a more aggressive feature is limited to BRAF mutated cases.

We further explore the hypothesis that the frequency of mutations may differ according to age groups. Therefore, patients were subdivided into 20-year age groups. The overall prevalence of BRAF V600E and RET/PTC is similar among age groups (ranging from 49 to $53 \%$ and 27 to $31 \%$, respectively). However, the prevalence of BRAF V600E, RET/PTC and RAS alone was higher among younger patients (20-39 years) and declined with age, especially when compared to older individuals ( $\geq 60$ years). Instead, the prevalence of tumors with concomitant mutation increased with patient age (Fig. 2B). Interestingly, the TCGA researchers found that mutation densities correlated with age and were not associated with other variables like genotype or radiation exposure. Precisely, five BRAF V600E mutant tumors with aggressive behavior had higher mutation densities (26).

\section{Association of mutational status with clinical course of disease}

Follow-up (2-16 years; median 7.75 years) shows that most patients $(74 \% ; n=87)$ have no evidence of disease. Recurrence was observed in 15 out of 118 patients (13\%). Nearly $53 \%(8 / 15)$ of recurrences were detected within the first 3 years of follow-up and $80 \%(12 / 15)$ were detected within 4 years. All patients who recurred were classified as high risk at initial diagnosis and had metastases to central or lateral compartment $(n=10)$, lung $(n=4)$ and bone $(n=1)$. Sixty-seven percent $(10 / 15)$ of patients who developed recurrent disease harbored BRAF V600E mutation alone or in association with RET/PTC2 (Table 3).

\section{Mutational status helps to identify a more aggressive behavior in small PTC, primarily in microPTC}

We initially investigated whether $B R A F, R E T / P T C$ or $R A S$ could predict a more aggressive phenotype of small PTC $(\leq 20 \mathrm{~mm})$ and, therefore, could improve preoperative risk 
Table 1 Summary of studies with concomitant RET/PTC rearrangement and BRAF V600E mutation in PTCs.

\begin{tabular}{|c|c|c|}
\hline References & $n$ & Total \\
\hline (68) & 137 & $3(2 \%)$ \\
\hline (69) & 11 & $1(9 \%)$ \\
\hline (70) & 60 & $2(3 \%)$ \\
\hline$(71)^{a}$ & 23 & $1(4 \%)$ \\
\hline (72) & 32 & $2(6 \%)$ \\
\hline$(56)^{a}$ & 65 & $5(8 \%)$ \\
\hline (42) & 78 & $4(5 \%)$ \\
\hline (73) & 125 & $5(4 \%)$ \\
\hline (54) & 54 & $5(9 \%)$ \\
\hline (74) & 107 & $6(6 \%)$ \\
\hline (75) & 266 & $1(0.4 \%)$ \\
\hline (76) & 70 & $4(6 \%)$ \\
\hline (53) & 72 & $14(19 \%)$ \\
\hline$(55)^{a}$ & 88 & $7(8 \%)$ \\
\hline This study & 118 & $15(13 \%)$ \\
\hline Total & 1306 & $75(6 \%)$ \\
\hline
\end{tabular}

\begin{tabular}{|c|c|c|c|}
\hline \multicolumn{4}{|c|}{ BRAF V600E } \\
\hline RET/PTC1 & RET/PTC2 & RET/PTC3 & Multiples \\
\hline 0 & NE & $3 / 3$ & 0 \\
\hline $1 / 1$ & NE & 0 & 0 \\
\hline 0 & NE & $2 / 2$ & 0 \\
\hline 0 & NE & $1 / 1$ & 0 \\
\hline $1 / 2(50 \%)$ & NE & $1 / 2(50 \%)$ & 0 \\
\hline $2 / 5(40 \%)$ & NE & $3 / 5(60 \%)$ & 0 \\
\hline $1 / 4(25 \%)$ & NE & $3 / 4(75 \%)$ & 0 \\
\hline $3 / 5(60 \%)$ & NE & $2 / 5(40 \%)$ & 0 \\
\hline 0 & $2 / 5(40 \%)$ & $3 / 5(60 \%)$ & 0 \\
\hline $6 / 6$ & 0 & 0 & 0 \\
\hline 0 & NE & $1 / 1$ & 0 \\
\hline $3 / 4(75 \%)$ & NE & $1 / 4(25 \%)$ & 0 \\
\hline $4 / 14(29 \%)$ & NE & $9 / 14(64 \%)$ & $1 / 14(7 \%)$ \\
\hline $7 / 7$ & 0 & 0 & 0 \\
\hline $3 / 15(20 \%)$ & $9 / 15(60 \%)$ & $2 / 15(13 \%)$ & $1 / 15(7 \%)$ \\
\hline $31 / 75(41 \%)$ & $11 / 75(15 \%)$ & $31 / 75(41 \%)$ & $2 / 75(3 \%)$ \\
\hline
\end{tabular}

$\mathrm{NE}$, not evaluated.

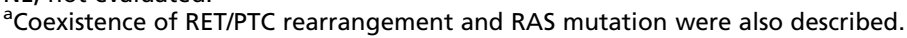

stratification and management of this set of thyroid tumors. When the presence of any mutation along MAPK pathway was investigated, we observed an association with presence of lymph node metastases $(P=0.020)$ and high risk $(P=0.047)$. However, when each mutation was considered independently, only BRAF V600E mutation was significantly associated with these clinicopathological parameters (Table 4).

When considering tumors measuring $\leq 10 \mathrm{~mm}$, no association was found (Table 4). Although not statistically significant, $64 \%$ (7/11) of microPTC with lymph node metastasis at diagnosis were positive for BRAF V600E alone or associated with RET/PTC, while only 35\% (8/23) of non-metastatic microPTC were positive for BRAF V600E (Table 4). None of RAS or RET/PTC-positive microPTC had lymph node metastasis at diagnosis.

As it has been suggested that the selected cut-off size of $10 \mathrm{~mm}$ can be further refined, we investigated whether there is a relationship between tumor size and clinicopathological parameters associated with recurrence and death or the presence of BRAF V600E mutation in this subgroup. We found that extrathyroidal invasion $(8.7 \pm 0.71, P=0.023)$, presence of lymph node metastases $(8.2 \pm 0.48, P=0.028)$, high risk $(8.6 \pm 0.39, P<0.001)$ and BRAF V600E mutation $(7.8 \pm 0.38, P=0.049)$ were significantly more frequent in tumors measuring $7-10 \mathrm{~mm}$ than smaller tumors (Fig. 2C). Although not significant, recurrence was more frequent in larger tumors $(8.5 \pm 0.64$ vs $6.6 \pm 0.41$; Fig. 2C).
Loss of expression of NIS and TPO is associated with the presence of BRAF V600E mutation, independently of tumor size

We next investigated the effect of different mutations along MAPK in the expression of thyroid iodine-metabolizing genes. Overall, the expression of NIS and TPO was lower in BRAF V600E-positive tumor than in tumors negative for the five-mutation panel and normal thyroid (Fig. 3A). Although the expression of $P D S$ and $T G$ was lower in BRAF V600E-positive tumors than normal thyroid, the difference was not statistically significant and the expression of TSHR was similar in all subgroups (data not shown). In contrast, neither RET/PTC nor NRAS Q61 modulates the expression of NIS and TPO (Fig. 3A). The expression pattern observed in PTCs harboring coincident mutations was similar to that observed in samples harboring BRAF V600E alone (Fig. 3A).

When considering the expression according to tumor size, NIS level was significantly lower in PTCs measuring $>10 \mathrm{~mm}$ (i.e. $11-20 \mathrm{~mm}$ and $>20 \mathrm{~mm}$ ). Regarding TPO, the expression levels were consistently lower in all PTCs, independently of tumor size (Fig. 3B).

As in microPTC, the expression of NIS was comparable to the expression observed in a normal thyroid, we assessed the expression of NIS and TPO in these tumors classified according to mutational status. NIS and TPO expression were consistently lower in microPTC that were BRAF V600E-positive or with concomitant mutations (Fig. 4A). 


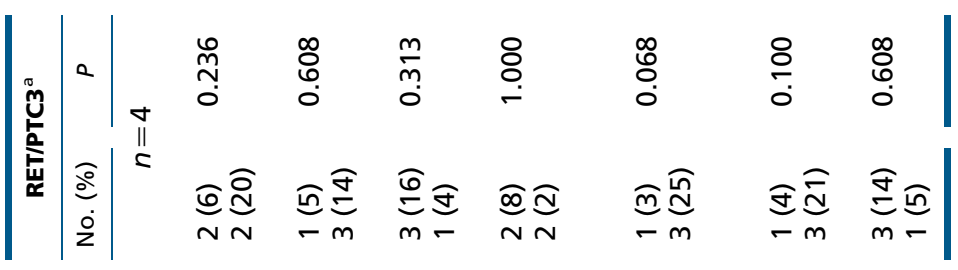

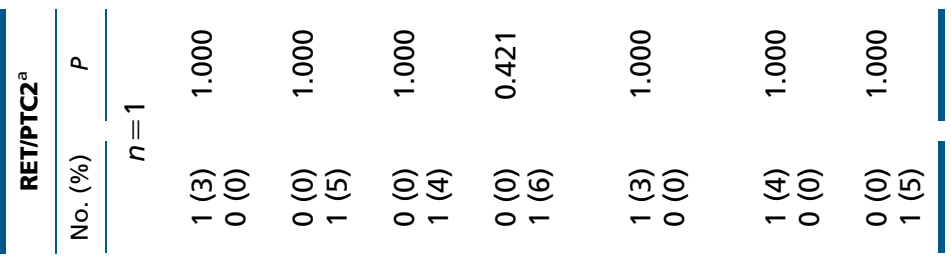

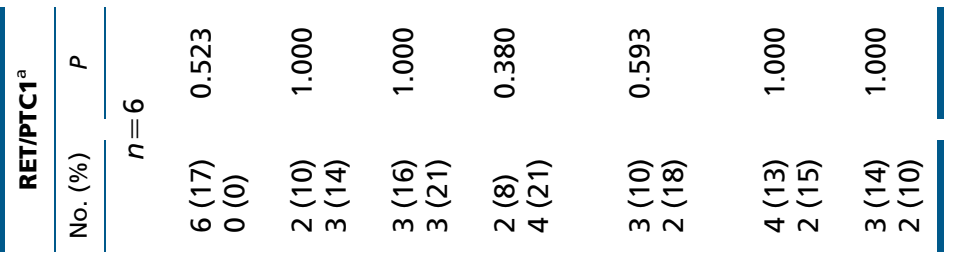

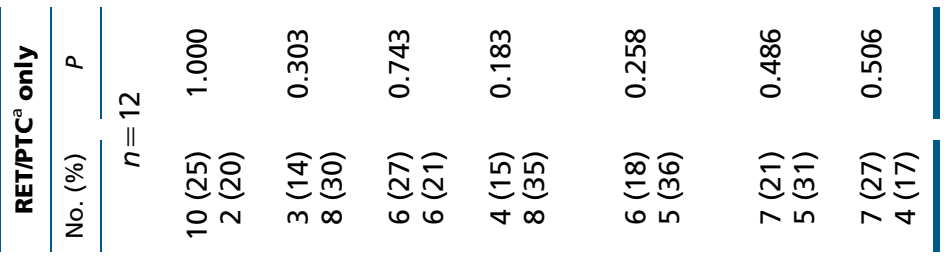

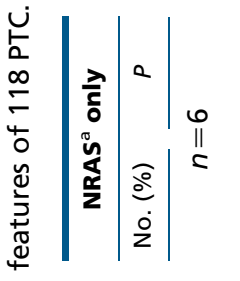

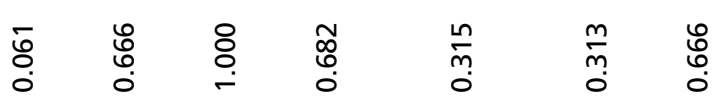

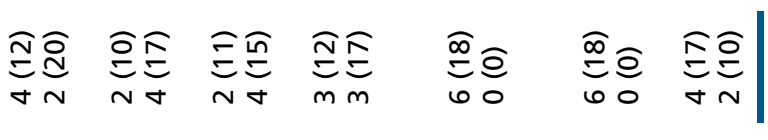

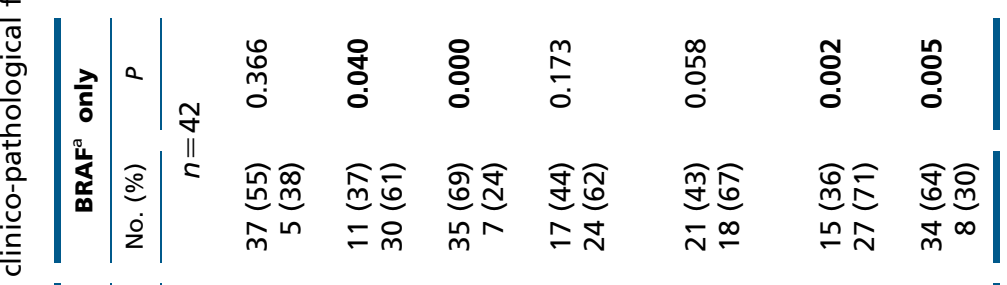

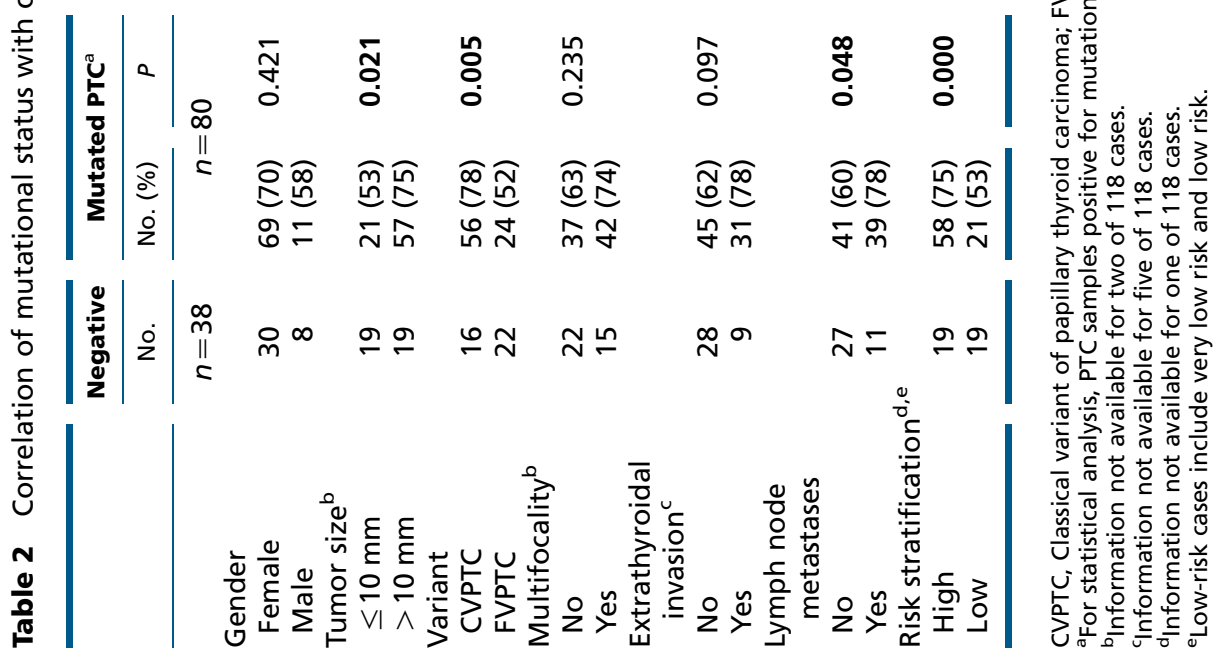




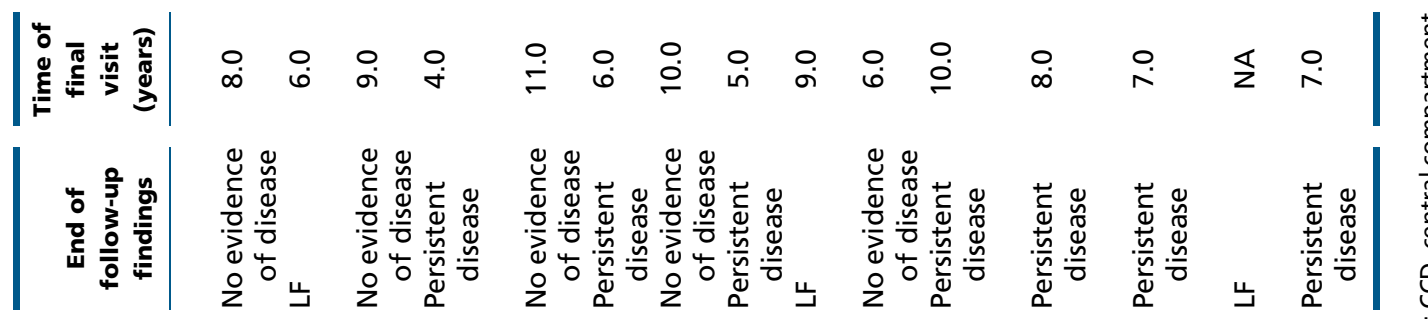

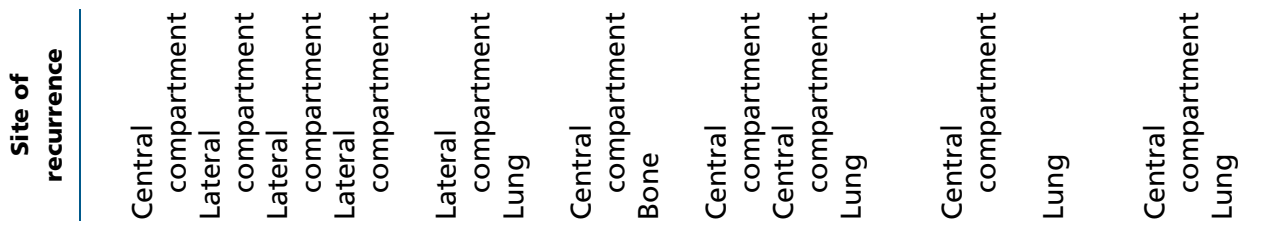

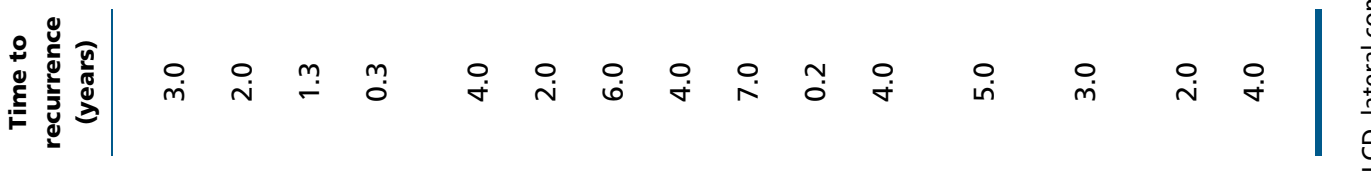

जิ

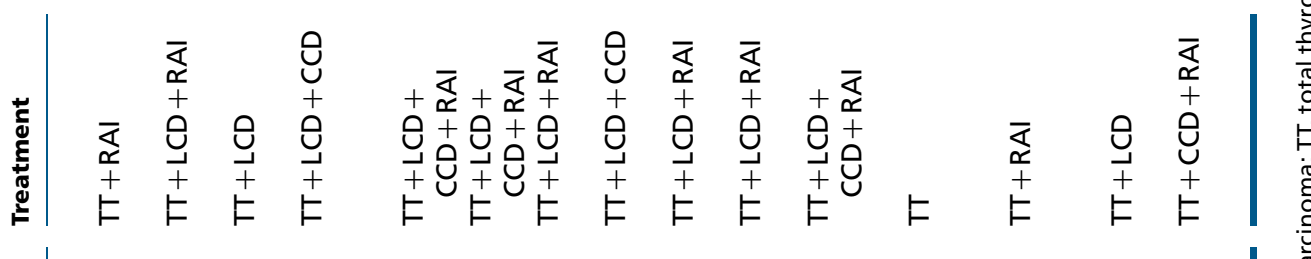

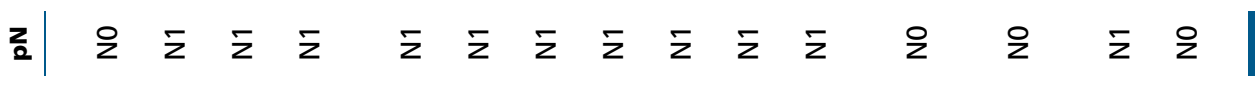

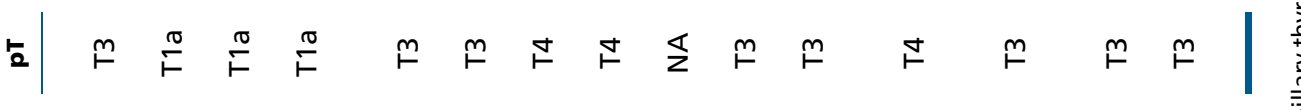

兹|

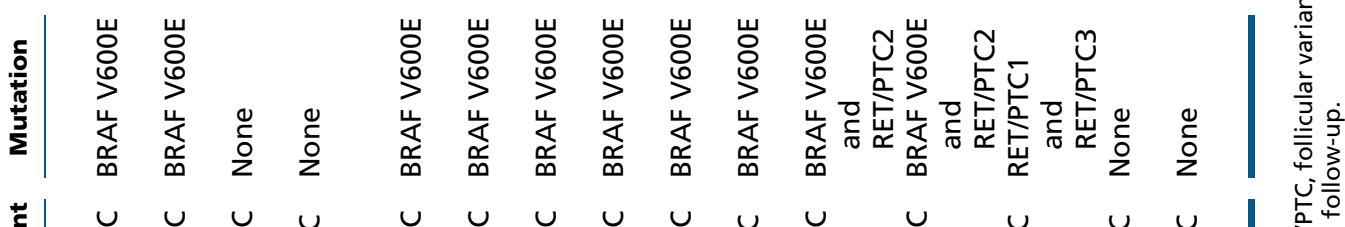

売|

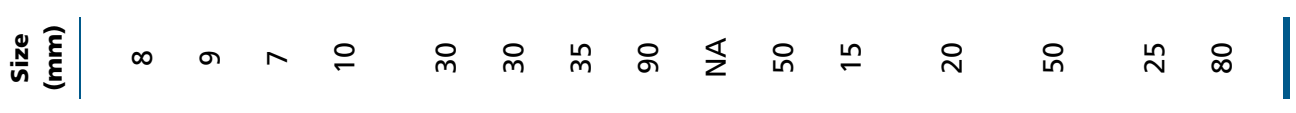

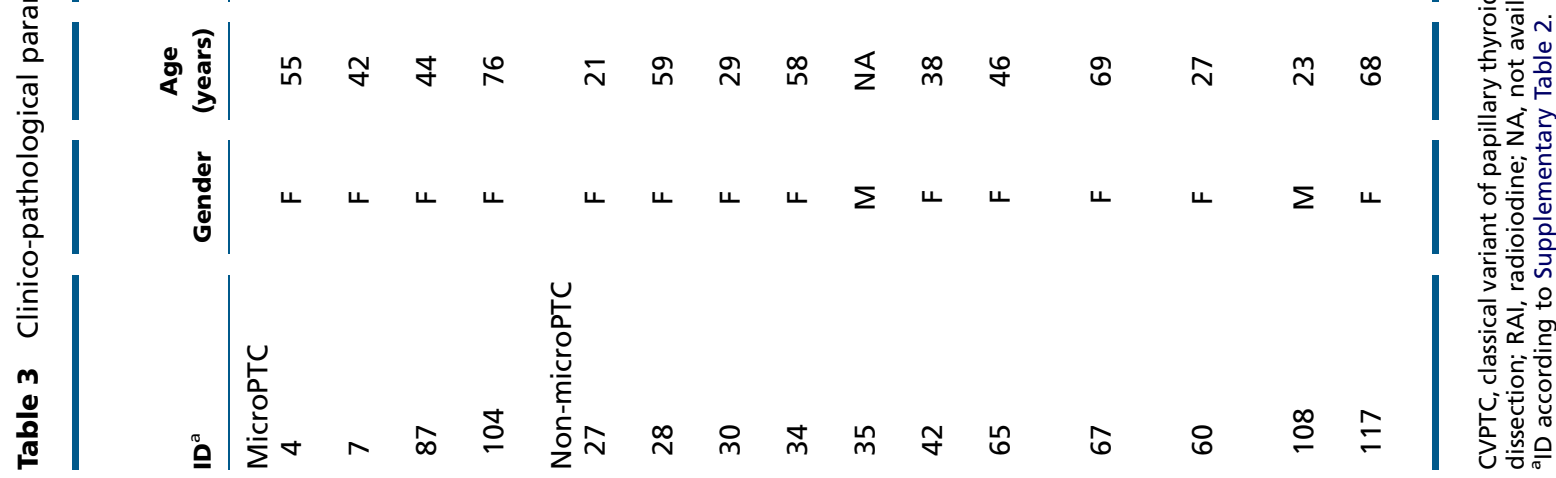

. 


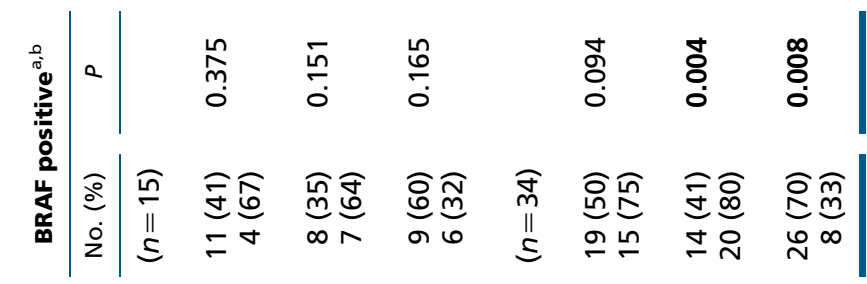

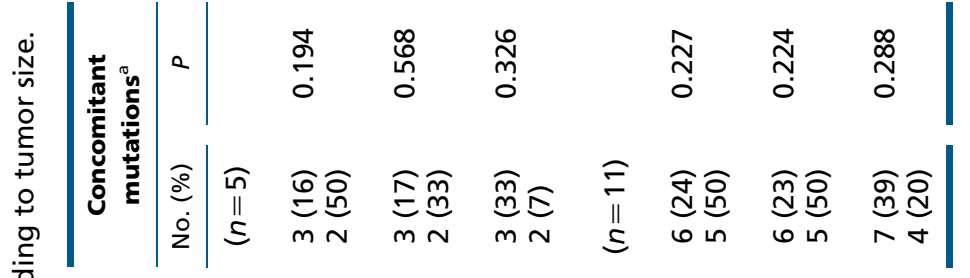

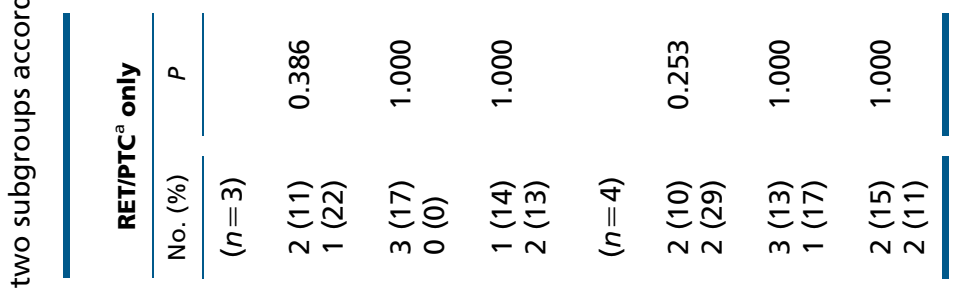

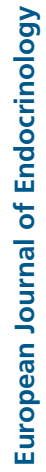

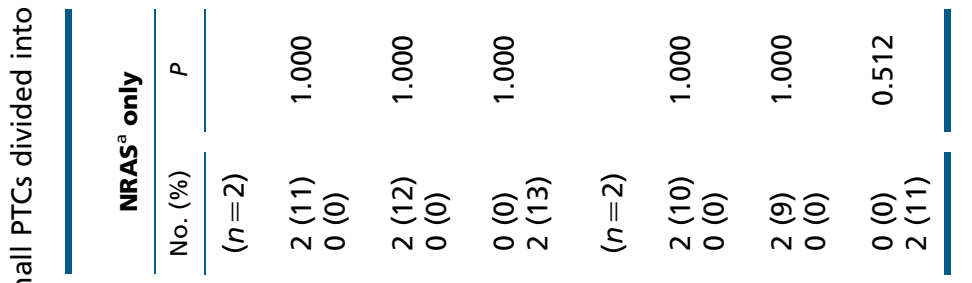

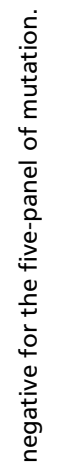

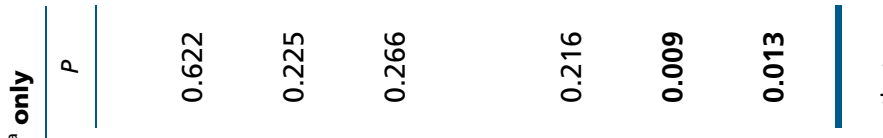

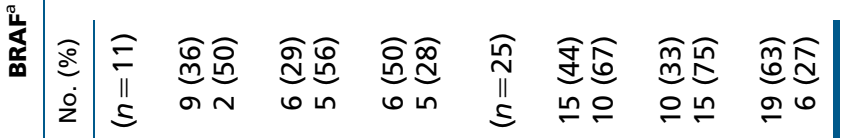

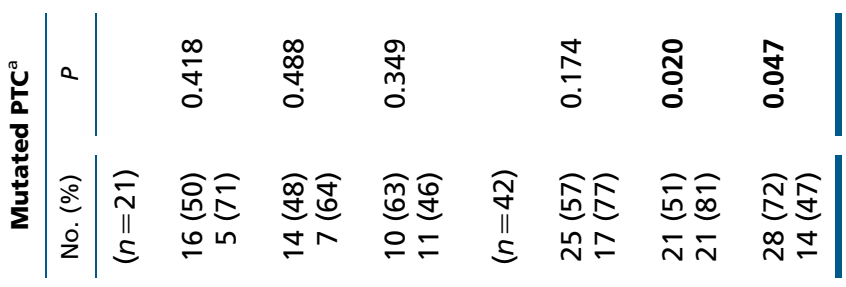

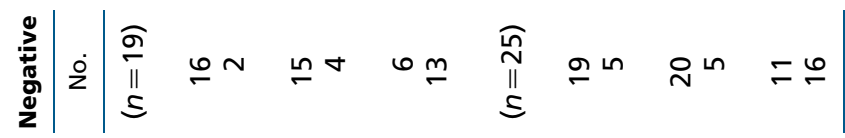

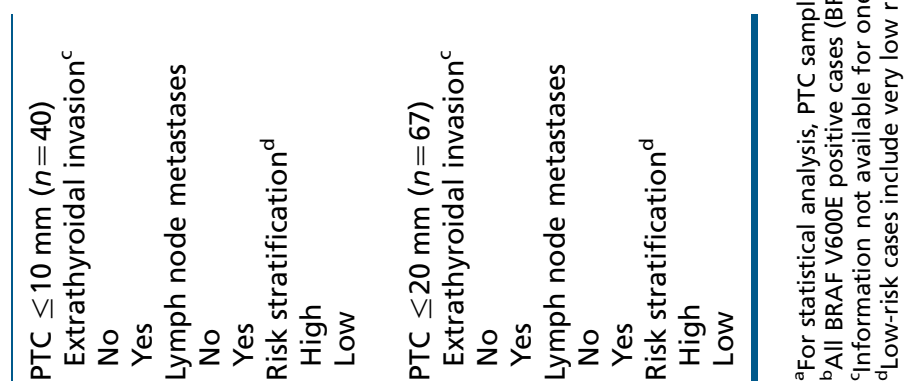



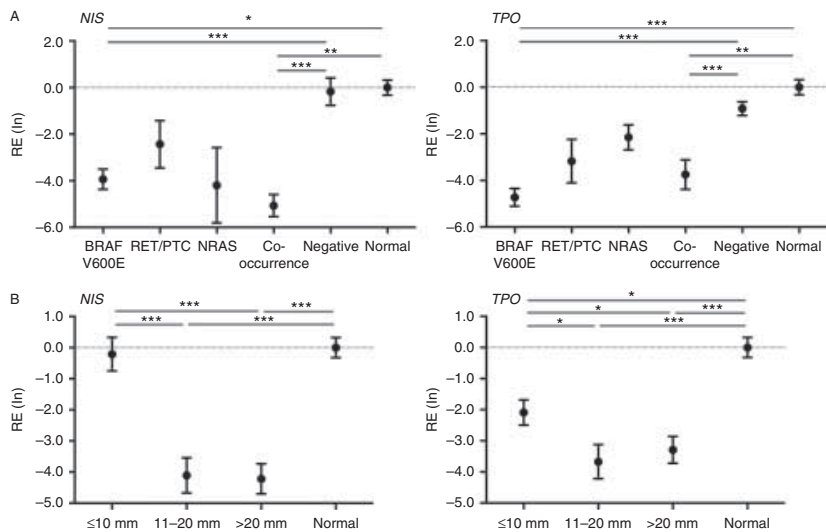

\section{Figure 3}

Relative expression (RE) of NIS and TPO in PTC. (A) Expression of NIS and TPO classified according to the mutational status. Negative groups correspond to those samples negative for the five-mutation panel $(n=38)$. (B) NIS expression is diminished in PTC measuring $11-20 \mathrm{~mm}$ and $>20 \mathrm{~mm}$. TPO expression is diminished in all PTC, independently of tumor size. Symbols represent means and bars represent the S.E.M. ${ }^{\star} P<0.05$; $* * P<0.01$ and $* * * P<0.001$.

Finally, as pathological features indicative of more aggressive behavior and BRAF V600E were found mainly in microPTC with $\geq 7 \mathrm{~mm}$, we also investigated the expression level of NIS and TPO in these set of tumors. Interestingly, the expression of NIS and TPO was consistently lower in microPTC measuring $\geq 7 \mathrm{~mm}(n=25)$ than tumors with $<7 \mathrm{~mm}(n=15)$ (Fig. 4B). These findings suggest that the diminished expression of NIS and TPO in microPTC is more likely to be associated with the presence of $B R A F$ mutation and more aggressive phenotype.

\section{Discussion}

The increasing incidence of thyroid cancer is primarily due to increased detection of small PTC. Therefore, the management of these small tumors, mainly microPTC, turned out to be one of the most relevant clinical problems in endocrinology. Though most microPTC are classified as low-risk tumors and, therefore, less prone to recur and can be successfully treated with a more conservative approach, a substantial percentage of the cases have extrathyroidal extension and lymph node metastases at presentation; a small number of these tumors may have distant metastases $(7,37)$. These findings suggest that microPTC may include two subgroups with distinct biological behavior. As parameters of the tumor are still unknown, currently it is not possible to distinguish those tumors that are within the good prognosis group from those that are within the poor prognosis group. In fact, there is no consensus in the literature to support either a more conservative approach or a more aggressive treatment. Hence, it is of clinical value to identify a molecular marker that can preoperatively improve risk stratification and hence tailor the management of patients with small PTC, mostly microPTC.

The knowledge that BRAF V600E, RAS and RET/PTC are the major driver mutations in PTC has had a profound impact on preoperative diagnosis of thyroid nodules. Although still remaining controversial (38), it has been proposed that BRAFV600E can potentially be used as prognostic factor in the risk stratification of microPTC $(7,11,12,14,15,16,17,18,19,37,39)$. Regarding RET/PTC, only a limited number of studies have evaluated its prognostic value. Some studies were unable to find any significant association between the presence of RET rearrangements and several clinical pathological features of aggressiveness $(21,40,41)$. Few studies suggested that RET/PTC3 correlates with more advanced stage of disease $(42,43)$ and aggressive variants such as solid (33) or tall-cell (44). Additionally, RET/PTC3 transgenic mice developed locally invasive solid PTC with lymph node metastases (45). Other studies reported that RET/PTC
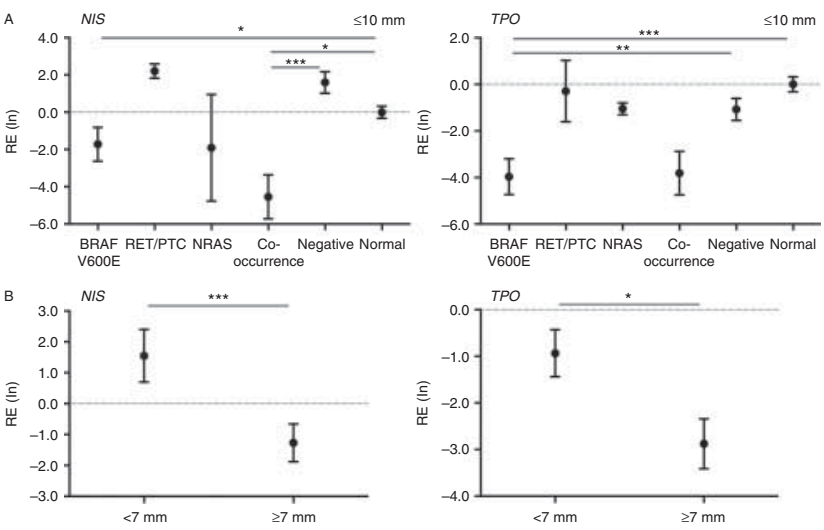

\section{Figure 4}

Relative expression (RE) of NIS and TPO in microPTC. (A) The expressions of NIS and TPO are lower in BRAF V600E-positive PTC (BRAF V600E only and concomitant mutations), compared to normal thyroid tissues or PTC that are negative for the five-mutation panel. (B) NIS and TPO expression are lower in microPTC, measuring $\geq 7 \mathrm{~mm}$ than microPTC measuring $<7 \mathrm{~mm}$. Symbols represent means and bars represent the S.E.M. $\star P<0.05 ; * * P<0.01$ and $* * * P<0.001$. 
rearrangements are significantly more common in smaller and less aggressive PTC, which points toward a good prognosis impact $(8,46)$.

Despite a number of descriptive reports on the prevalence of BRAF or RET/PTC mutations in microPTC and their correlation with clinico-pathological characteristics, there has been no analysis that evaluated the prognostic value of different mutations along with MAPK in the same series of microPTC. We considered this essential, as most studies correlate clinico-pathological parameters between BRAF-positive and BRAF-negative tumors. As RAS or RET/PTC are commonly found in PTC and were not investigated, the BRAF-negative group possibly includes cases that are indeed positive for these mutations.

In this study, we investigated the prevalence of NRAS Q61 mutations and RET/PTC rearrangements in a large series of PTC in which BRAF V600E mutational status was previously determined (13). The overall rate of BRAF V600E mutation is $48 \%, R E T / P T C$ is $27 \%$ and NRAS is $9 \%$. In few tumors, concomitant mutations along the MAPK pathway were identified.

It is worth mentioning that in most series mutations in genes within the MAPK pathway, they rarely co-occur in PTC $(9,47,48,49)$. Data from the Cancer Genome Atlas also showed that mutations in the MAPK-related genes were virtually mutually exclusive. BRAF, NRAS, KRAS and $H R A S$ were present in the majority of tumor cells, i.e. they are largely clonal. The authors reported one PTC case with two driver mutations in the MAPK-related genes. In these tumors, KRAS mutation was clonal while BRAF was subclonal (26). Most likely, the mutually exclusive pattern occurs in most tumors, mainly with clonal origin. However, coincident mutations in genes that encode proteins along the MAPK pathway have been previously reported in thyroid tumors, as shown in Table 1. Furthermore, using high-throughput mutation profiling in 1000 human tumor samples, a high number of co-occurring mutations in the same pathway were detected in several tumor types. The authors found that BRAF mutations involving codon 600 and 601 were likely to co-occur with a RAS family mutation (50). Simultaneous BRAF and RAS mutations were also reported well as in the breast, gynecologic malignancies and colon $(51,52)$.

Comparable to our findings, other groups reported that BRAF V600E was associated with more aggressive tumor phenotype. RET/PTC alone or combined with BRAF V600E did not represent a risk factor for a more aggressive disease (53). However, few studies suggested that multiple genetic changes might be associated with tumor progression $(52,54,55)$. Henderson et al. (54) reported that prevalence of tumors with simultaneous BRAF and RET/PTC mutations in the recurrent population far exceeds the prevalence reported for patients with primary PTC. Zou et al. (55) found that concomitant mutations are a frequent event in advanced PTC and are associated with poor response to treatment and shorter disease-free survival. The authors examined different tumors sections from samples with BRAF V600E and RAS mutations. BRAF V600E mutation was found in all sections from the same tumor while RAS mutation was detected only in some sections. Based on these findings, the authors suggested that concomitant mutations may represent intratumoral heterogeneity and it is likely that RAS mutation occurred later than BRAF, and might play a role in disease progression (55). Evidence for intratumoral genetic heterogeneity of PTC involving both RET/PTC and BRAF has also been previously reported $(56,57)$.

Remarkably, our study found that the prevalence of BRAF, RET/PTC and RAS mutations alone decreases with age, whereas the incidence of concomitant mutations increases with age. Regarding the association between older age and increased prevalence of concomitant mutation, it was previously reported that most cases of PTC with concomitant mutations occurred in patients older than 45 years of age $(54,55)$.

Finally, the discrepancy may be a result of different sensitivities of the detection methods, mainly if RET/PTC is present in a small fraction of cells. Using FISH analysis and PCR-based assays that detect expression of RET/PTC transcripts, it was demonstrated that the presence of RET/PTC rearrangement within each tumor can vary from involving almost all tumors cells to only a small proportion of cells (56).

Our study used standard RT-PCR for detection of RET/PTC rearrangement, since the authors suggested this method is sufficient to detected RET/PTC in all tumors with at least $17 \%$ of cells harboring RET/PTC rearrangements. To confirm the expression of RET fusion transcripts, we additionally evaluated the expression of both the TK and EC domains of RET was performed, as described $(31,32,33,34,35,36)$.

All together, tumor heterogeneity, age of patients and methodology used may explain the divergence obtained in different series.

We next determined the prevalence of BRAF V600E, NRAS Q61 and RET/PTC in microPTC. While it has been suggested that RET/PTC rearrangements are particularly more prevalent in microPTCs than in clinically evident PTCs $(41,46)$, in our study no differences were found in the prevalence of RET/PTC and RAS in these subgroups. 
Our study, however, confirmed the increased prevalence of BRAF V600E in tumors measuring $>10 \mathrm{~mm}$ than in microPTC. Regarding prognosis implications, BRAF V600E was associated with larger tumor size, presence of lymph node metastases at diagnosis and higher risk of recurrence. RET/PTC and RAS were not correlated with clinicalpathological parameters indicative of a more aggressive phenotype.

Recently, a few groups have suggested that tumor size alone is not a significant predictor of tumor persistence or recurrence and, therefore, thyroidectomy and postoperative radioactive iodine ablation should be performed in patients whose one or more parameters such as multicentricity, positive lymph nodes, or capsular or vessel invasion are found $(5,58)$. Consequently, it has been suggested that the selected cut-off size of $10 \mathrm{~mm}$ may be too arbitrary and can be further refined (59). There is a trend to use cut-off value of $7 \mathrm{~mm}$ as a reasonable threshold for aggressiveness in microPTC (60), although other groups have suggested cut-off values from $5 \mathrm{~mm}$ to $9 \mathrm{~mm}$.

In an attempt to better separate those microPTC that have more aggressive features from those tumors that have a limited disease, we correlated tumor size with BRAF V600E or clinical-pathological parameters of aggressiveness. The present study showed that extrathyroidal invasion, presence of metastases at diagnosis, high risk of recurrence and the presence of BRAF V600E mutation were significantly more prevalent in tumors measuring $\geq 7 \mathrm{~mm}$.

Although current data suggest that RAI is of no benefit in preventing recurrence in microPTC (4), some cases show high metastatic potential and high persistence/ recurrence rate justifying a more aggressive treatment. As BRAF V600E mutation is frequently found in tumors that are refractory to treatment with radioiodine (25) and small-molecule MAPK inhibitors restore the expression of thyroid-specific genes with consequent restoration of RAI uptake (61), it seems rational to explore whether BRAF V600E, NRAS Q61 or RET/PTC modulate the expression of proteins associated with iodine metabolism and may explain why some microPTC could be less responsive to RAI therapy and, therefore, RAI did not prevent the recurrence rate of some microPTC $(59,62)$.

This study showed that the expressions of NIS and TPO were significantly lower in PTC with BRAF mutations. No difference was observed in the expression of genes that code for proteins involved in iodine metabolism in PTC samples bearing RAS mutations or RET/PTC rearrangements.

The distinct expression profile of genes involved in iodine-uptake and metabolism between BRAF-V600E and
RAS-mutant tumors has been also confirmed in other studies $(49,63,64,65,66,67)$.

Recently, using exome and RNA sequencing data, the TCGA study group evaluated the spectrum of gene signature in BRAF V600E-mutated and RAS-mutated tumors. This signature showed strong separation between BRAF V600E and RAS-driven tumors. Therefore, they developed a score system, which quantify the extent to which the expression profile of a given tumor resembles either BRAF V600E or RAS-mutant profiles, the BRAF V600E and RAS Score (BRS). Next, they used BRS as a reference to interrogate the signaling consequences of less common mutations. All BRAF mutations other than BRAF V600E and BRAF fusions, PAX8/PPARG fusion and most EIF1AX mutations exhibited RAS-like behaviors. Nearly all of the RET/PTC were weekly BRAF-like and NTRK3 and ALK fusion were largely neutral (26).

Next, they summarized the expression levels of thyroid metabolism and function genes to produce a score metric designated thyroid differentiation score (TDS). Even they are based on different signature, BRS and TDS measures were highly correlated across all tumors. The BRS and TDS score also correlated with different omics data and histology. In other words, BRAF V600E-Like comprise mainly less differentiated tall and classic variants of PTC, signaling preferentially through MAPK and downregulated expression of genes involved in iodine metabolism. Interestingly, BRAF V600E-like is less homogeneous than initially considered, containing distinct subgroups. The RAS-like PTCs result in highly differentiated tumors enriched for follicular variant, low risk of recurrence, occurs in young patients, less prominent levels of MAPK signaling and lower effect on the genes associated with iodine-uptake and metabolism (26).

All together, regarding the expression profile of genes involved in iodine-uptake and metabolism, our data is in agreement with TCGA study group. BRAF-mutant tumors showed lower expression of TPO, compared to RET/PTC and RAS-mutant tumors. Although very few samples with RET/PTC1 and RET/PTC3 exhibited BRAF V600E-like behavior, a large proportion has a RAS-Like behavior.

Remarkably, when we stratified microPTC according to mutational status, the expression of NIS and TPO were significantly diminished in BRAF V600E-positive microPTC. Finally, NIS and TPO expression were significantly lower in microPTC with $\geq 7 \mathrm{~mm}$.

As nearly $87 \%$ of PTC detected consisted of tumors measuring $20 \mathrm{~mm}$ or less, we also explored an association between BRAF V600E mutations with different clinicopathological features associated with poor prognosis in 
PTC measuring $\leq 20 \mathrm{~mm}$. We found an association between BRAF V600E and presence of lymph node metastases and higher risk of recurrence. Our findings corroborate with those previously reported, in which the authors suggested that BRAF V600E is useful to improve risk stratification even for tumors measuring $\leq 20 \mathrm{~mm}$ that are limited to the thyroid gland and, therefore, classified as low risk tumors (17). Nevertheless, when we considered only tumors measuring $10 \mathrm{~mm}$ or less, no significant association was found between mutational profiling and clinico-pathological parameters.

In summary, BRAF V600E mutation was associated with clinico-pathological parameters that are associated with more aggressive phenotype in small PTC. A strong association was also found in microPTC larger than $7 \mathrm{~mm}$, suggesting that this subgroup of microPTC is more prone to recur. Moreover, $B R A F$-mutated cases showed lower expression of genes involved in iodine uptake, which points for an effect of $B R A F$ on the expression of these genes. These findings are similar to the data found in larger aggressive PTC, suggesting that, although microPTC are considered clinically indolent, the subgroup of 7-10 mm might be treated as conventional PTC. We believe that our findings will help to decide the realistic usefulness of BRAF V600E mutation as preoperative marker of poor prognosis in small PTC, even in microPTC.

\section{Supplementary data}

This is linked to the online version of the paper at http://dx.doi.org/10.1530/ EJE-15-0254.

\section{Declaration of interest}

The authors declare that there is no conflict of interest that could be perceived as prejudicing the impartiality of the research reported.

\section{Funding}

The study was supported by research grants from the São Paulo State Research Foundation (FAPESP), grant numbers 11/10787-2, 12/02902-9 and 2013/03867-5 and from the Brazilian Research Council (CNPq), grant number (470441/2013-5). A U Bastos (12/06221-6), G Oler (12/17545-7) and B H N Nozima (12/02325-1) are FAPESP scholars. J M Cerutti is an investigator with the CNPq.

\section{References}

1 Davies L \& Welch HG. Increasing incidence of thyroid cancer in the united states, 1973-2002. Journal of the American Medical Association 2006295 2164-2167. (doi:10.1001/jama.295.18.2164)

2 Roti E, Rossi R, Trasforini G, Bertelli F, Ambrosio MR, Busutti L, Pearce EN, Braverman LE \& Degli Uberti EC. Clinical and histological characteristics of papillary thyroid microcarcinoma: results of a retrospective study in 243 patients. Journal of Clinical Endocrinology and Metabolism 200691 2171-2178. (doi:10.1210/jc.2005-2372)

3 Pellegriti G, Frasca F, Regalbuto C, Squatrito S \& Vigneri R. Worldwide increasing incidence of thyroid cancer: Update on epidemiology and risk factors. Journal of Cancer Epidemiology 20132013965212. (doi:10.1155/2013/965212)

4 Cooper DS, Doherty GM, Haugen BR, Kloos RT, Lee SL, Mandel SJ, Mazzaferri EL, McIver B, Pacini F, Schlumberger M et al. Revised american thyroid association management guidelines for patients with thyroid nodules and differentiated thyroid cancer. Thyroid 200919 1167-1214. (doi:10.1089/thy.2009.0110)

5 Mazzaferri EL. Managing thyroid microcarcinomas. Yonsei Medical Journal 201253 1-14. (doi:10.3349/ymj.2012.53.1.1)

6 Wartofsky L. Management of papillary microcarcinoma: primum non nocere? Journal of Clinical Endocrinology and Metabolism 201297 1169-1172. (doi:10.1210/jc.2012-1465)

7 Niemeier LA, Kuffner Akatsu H, Song C, Carty SE, Hodak SP, Yip L, Ferris RL, Tseng GC, Seethala RR, Lebeau SO, Stang MT, Coyne C, Johnson JT, Stewart AF \& Nikiforov YE. A combined molecularpathologic score improves risk stratification of thyroid papillary microcarcinoma. Cancer 2012118 2069-2077. (doi:10.1002/ cncr.26425)

8 Menicali E, Moretti S, Voce P, Romagnoli S, Avenia N \& Puxeddu E. Intracellular signal transduction and modification of the tumor microenvironment induced by ret/ptcs in papillary thyroid carcinoma. Frontiers in Endocrinology 20123 67. (doi:10.3389/fendo.2012.00067)

9 Adeniran AJ, Zhu Z, Gandhi M, Steward DL, Fidler JP, Giordano TJ, Biddinger PW \& Nikiforov YE. Correlation between genetic alterations and microscopic features, clinical manifestations, and prognostic characteristics of thyroid papillary carcinomas. American Journal of Surgical Pathology 200630 216-222. (doi:10.1097/01.pas.0000176432. 73455.1b)

10 Xing M. Braf mutation in papillary thyroid cancer: pathogenic role, molecular bases, and clinical implications. Endocrine reviews 200728 742-762. (doi:10.1210/er.2007-0007)

11 Xing M, Alzahrani AS, Carson KA, Viola D, Elisei R, Bendlova B, Yip L, Mian C, Vianello F, Tuttle RM et al. Association between braf v600e mutation and mortality in patients with papillary thyroid cancer. Journal of the American Medical Association 2013309 1493-1501. (doi:10.1001/jama.2013.3190)

12 Xing M, Alzahrani AS, Carson KA, Shong YK, Kim TY, Viola D, Elisei R, Bendlova B, Yip L, Mian C et al. Association between braf v600e mutation and recurrence of papillary thyroid cancer. Journal of clinical oncology 201533 42-50. (doi:10.1200/JCO.2014.56.8253)

13 Oler G \& Cerutti JM. High prevalence of braf mutation in a brazilian cohort of patients with sporadic papillary thyroid carcinomas: correlation with more aggressive phenotype and decreased expression of iodide-metabolizing genes. Cancer 2009115 972-980. (doi:10.1002/ cncr.24118)

14 Lin KL, Wang OC, Zhang XH, Dai XX, Hu XQ \& Qu JM. The braf mutation is predictive of aggressive clinicopathological characteristics in papillary thyroid microcarcinoma. Annals of Surgical Oncology 2010 17 3294-3300. (doi:10.1245/s10434-010-1129-6)

15 Virk RK, Van Dyke AL, Finkelstein A, Prasad A, Gibson J, Hui P, Theoharis CG, Carling T, Roman SA, Sosa JA et al. Brafv600e mutation in papillary thyroid microcarcinoma: a genotype-phenotype correlation. Modern Pathology 201326 62-70. (doi:10.1038/modpathol. 2012.152)

16 Lee X, Gao M, Ji Y, Yu Y, Feng Y, Li Y, Zhang Y, Cheng W \& Zhao W. Analysis of differential braf(v600e) mutational status in high aggressive papillary thyroid microcarcinoma. Annals of Surgical Oncology 200916 240-245. (doi:10.1245/s10434-008-0233-3)

17 Basolo F, Torregrossa L, Giannini R, Miccoli M, Lupi C, Sensi E, Berti P, Elisei R, Vitti P, Baggiani A et al. Correlation between the braf v600e mutation and tumor invasiveness in papillary thyroid carcinomas 
smaller than 20 millimeters: analysis of 1060 cases. Journal of Clinical Endocrinology and Metabolism 201095 4197-4205. (doi:10.1210/ jc.2010-0337)

18 Nucera C \& Pontecorvi A. Clinical outcome, role of braf(v600e), and molecular pathways in papillary thyroid microcarcinoma: is it an indolent cancer or an early stage of papillary thyroid cancer? Frontiers in Endocrinology 20123 33. (doi:10.3389/fendo.2012.00033)

19 Rossi ED, Martini M, Capodimonti S, Lombardi CP, Pontecorvi A, Vellone VG, Zannoni GF, Larocca LM \& Fadda G. Braf (v600e) mutation analysis on liquid-based cytology-processed aspiration biopsies predicts bilaterality and lymph node involvement in papillary thyroid microcarcinoma. Cancer Cytopathology 2013121 291-297. (doi:10.1002/cncy.21258)

20 Li F, Chen G, Sheng C, Gusdon AM, Huang Y, Lv Z, Xu H, Xing M \& Qu S. Brafv600e mutation in papillary thyroid microcarcinoma: a meta-analysis. Endocrine-Related Cancer 201522 159-168. (doi:10.1530/ ERC-14-0531)

21 Soares P, Celestino R, Gaspar da Rocha A \& Sobrinho-Simoes M. Papillary thyroid microcarcinoma: how to diagnose and manage this epidemic? International Journal of Surgical Pathology 201422 113-119. (doi:10.1177/1066896913517394)

22 Arturi F, Russo D, Schlumberger M, du Villard JA, Caillou B, Vigneri P, Wicker R, Chiefari E, Suarez HG \& Filetti S. Iodide symporter gene expression in human thyroid tumors. Journal of Clinical Endocrinology and Metabolism 199883 2493-2496. (doi:10.1210/jcem. 83.7.4974)

23 Hou P, Liu D, Shan Y, Hu S, Studeman K, Condouris S, Wang Y, Trink A, El-Naggar AK, Tallini G et al. Genetic alterations and their relationship in the phosphatidylinositol 3-kinase/akt pathway in thyroid cancer. Clinical Cancer Research 200713 1161-1170. (doi:10.1158/1078-0432. CCR-06-1125)

24 Riesco-Eizaguirre G, Rodriguez I, De la Vieja A, Costamagna E, Carrasco N, Nistal M \& Santisteban P. The brafv600e oncogene induces transforming growth factor beta secretion leading to sodium iodide symporter repression and increased malignancy in thyroid cancer. Cancer Research 200969 8317-8325. (doi:10.1158/0008-5472. CAN-09-1248)

25 Xing M, Westra WH, Tufano RP, Cohen Y, Rosenbaum E, Rhoden KJ, Carson KA, Vasko V, Larin A, Tallini G et al. Braf mutation predicts a poorer clinical prognosis for papillary thyroid cancer. Journal of Clinical Endocrinology and Metabolism 200590 6373-6379. (doi:10.1210/ jc.2005-0987)

26 Cancer Genome Atlas Research N. Integrated genomic characterization of papillary thyroid carcinoma. Cell 2014159 676-690. (doi:10.1016/ j.cell.2014.09.050)

27 Pacini F, Schlumberger M, Dralle H, Elisei R, Smit JW \& Wiersinga W. European consensus for the management of patients with differentiated thyroid carcinoma of the follicular epithelium. European Journal of Endocrinology 2006 154 787-803. (doi:10.1530/eje. 1.02158)

28 Oler G, Ebina KN, Michaluart P Jr, Kimura ET \& Cerutti J. Investigation of braf mutation in a series of papillary thyroid carcinoma and matched-lymph node metastasis reveals a new mutation in metastasis. Clinical Endocrinology 200562 509-511. (doi:10.1111/j.1365-2265. 2005.02235.x)

29 Fenton CL, Lukes Y, Nicholson D, Dinauer CA, Francis GL \& Tuttle RM. The ret/ptc mutations are common in sporadic papillary thyroid carcinoma of children and young adults. Journal of Clinical Endocrinology and Metabolism 200085 1170-1175. (doi:10.1210/jcem.85.3.6472)

30 Oler G, Camacho CP, Hojaij FC, Michaluart P Jr, Riggins GJ \& Cerutti JM. Gene expression profiling of papillary thyroid carcinoma identifies transcripts correlated with braf mutational status and lymph node metastasis. Clinical Cancer Research 200814 4735-4742. (doi:10.1158/1078-0432.CCR-07-4372)

31 Rhoden KJ, Johnson C, Brandao G, Howe JG, Smith BR \& Tallini G. Real-time quantitative RT-PCR identifies distinct c-ret, ret/ptc1 and ret/ptc3 expression patterns in papillary thyroid carcinoma. Laboratory Investigation 200484 1557-1570. (doi:10.1038/labinvest.3700198)

32 Ricarte-Filho JC, Li S, Garcia-Rendueles ME, Montero-Conde C, Voza F, Knauf JA, Heguy A, Viale A, Bogdanova T, Thomas GA et al. Identification of kinase fusion oncogenes in post-chernobyl radiation-induced thyroid cancers. Journal of Clinical Investigation 2013 123 4935-4944. (doi:10.1172/JCI69766)

33 Nikiforov YE, Rowland JM, Bove KE, Monforte-Munoz H \& Fagin JA. Distinct pattern of ret oncogene rearrangements in morphological variants of radiation-induced and sporadic thyroid papillary carcinomas in children. Cancer Research 199757 1690-1694.

34 Sheu SY, Schwertheim S, Worm K, Grabellus F \& Schmid KW. Diffuse sclerosing variant of papillary thyroid carcinoma: lack of braf mutation but occurrence of ret/ptc rearrangements. Modern Pathology 200720 779-787. (doi:10.1038/modpathol.3800797)

35 Unger K, Zitzelsberger H, Salvatore G, Santoro M, Bogdanova T, Braselmann H, Kastner P, Zurnadzhy L, Tronko N, Hutzler P et al. Heterogeneity in the distribution of ret/ptc rearrangements within individual post-chernobyl papillary thyroid carcinomas. Journal of Clinical Endocrinology and Metabolism 200489 4272-4279. (doi:10.1210/ jc.2003-031870)

36 Elisei R, Romei C, Vorontsova T, Cosci B, Veremeychik V, Kuchinskaya E, Basolo F, Demidchik EP, Miccoli P, Pinchera A et al. Ret/ptc rearrangements in thyroid nodules: studies in irradiated and not irradiated, malignant and benign thyroid lesions in children and adults. Journal of Clinical Endocrinology and Metabolism 200186 3211-3216. (doi:10.1210/jcem.86.7.7678)

37 Rossi ED, Martini M, Fadda G \& Larocca LM. Papillary thyroid microcarcinoma: a painstaking category to manage. Clinical Endocrinology 201481 785-786. (doi:10.1111/cen.12413)

38 Walczyk A, Kowalska A, Kowalik A, Sygut J, Wypiorkiewicz E, Chodurska R, Pieciak L \& Gozdz S. The braf(v600e) mutation in papillary thyroid microcarcinoma: does the mutation have an impact on clinical outcome? Clinical Endocrinology 201480 899-904. (doi:10.1111/cen.12386)

39 Malandrino P, Pellegriti G, Attard M, Violi MA, Giordano C, Sciacca L, Regalbuto C, Squatrito S \& Vigneri R. Papillary thyroid microcarcinomas: a comparative study of the characteristics and risk factors at presentation in two cancer registries. Journal of Clinical Endocrinology and Metabolism 201398 1427-1434. (doi:10.1210/jc.2012-3728)

40 Puxeddu E, Moretti S, Giannico A, Martinelli M, Marino C, Avenia N, Cristofani R, Farabi R, Reboldi G, Ribacchi R et al. Ret/ptc activation does not influence clinical and pathological features of adult papillary thyroid carcinomas. European Journal of Endocrinology 2003148 505-513. (doi:10.1530/eje.0.1480505)

41 Tallini G, Ghossein RA, Emanuel J, Gill J, Kinder B, Dimich AB, Costa J, Robbins R, Burrow GN \& Rosai J. Detection of thyroglobulin, thyroid peroxidase, and ret/ptc1 mrna transcripts in the peripheral blood of patients with thyroid disease. Journal of clinical oncology 199816 1158-1166.

42 Romei C, Ciampi R, Faviana P, Agate L, Molinaro E, Bottici V, Basolo F, Miccoli P, Pacini F, Pinchera A et al. Brafv600e mutation, but not ret/ptc rearrangements, is correlated with a lower expression of both thyroperoxidase and sodium iodide symporter genes in papillary thyroid cancer. Endocrine-Related Cancer 200815 511-520. (doi:10.1677/ERC-07-0130)

43 Bongarzone I, Vigneri P, Mariani L, Collini P, Pilotti S \& Pierotti MA. Ret/ntrk1 rearrangements in thyroid gland tumors of the papillary carcinoma family: correlation with clinicopathological features. Clinical Cancer Research 19984 223-228.

44 Basolo F, Giannini R, Monaco C, Melillo RM, Carlomagno F, Pancrazi M, Salvatore G, Chiappetta G, Pacini F, Elisei R et al. Potent mitogenicity of the ret/ptc3 oncogene correlates with its prevalence in tall-cell variant of papillary thyroid carcinoma. American Journal of Pathology 2002160 247-254. (doi:10.1016/S0002-9440(10)64368-4) 
45 Powell DJ Jr, Russell J, Nibu K, Li G, Rhee E, Liao M, Goldstein M, Keane WM, Santoro M, Fusco A et al. The ret/ptc3 oncogene: metastatic solid-type papillary carcinomas in murine thyroids. Cancer Research $1998585523-5528$.

46 Viglietto G, Maglione D, Rambaldi M, Cerutti J, Romano A, Trapasso F, Fedele M, Ippolito P, Chiappetta G, Botti G et al. Upregulation of vascular endothelial growth factor (vegf) and downregulation of placenta growth factor (plgf) associated with malignancy in human thyroid tumors and cell lines. Oncogene 199511 1569-1579.

47 Kimura ET, Nikiforova MN, Zhu Z, Knauf JA, Nikiforov YE \& Fagin JA. High prevalence of braf mutations in thyroid cancer: genetic evidence for constitutive activation of the ret/ptc-ras-braf signaling pathway in papillary thyroid carcinoma. Cancer Research 200363 1454-1457.

48 Soares P, Trovisco V, Rocha AS, Lima J, Castro P, Preto A, Maximo V, Botelho T, Seruca R \& Sobrinho-Simoes M. Braf mutations and ret/ptc rearrangements are alternative events in the etiopathogenesis of ptc. Oncogene 200322 4578-4580. (doi:10.1038/sj.onc.1206706)

49 Giordano TJ, Kuick R, Thomas DG, Misek DE, Vinco M, Sanders D, Zhu Z, Ciampi R, Roh M, Shedden K et al. Molecular classification of papillary thyroid carcinoma: distinct braf, ras, and ret/ptc mutation-specific gene expression profiles discovered by DNA microarray analysis. Oncogene 200524 6646-6656. (doi:10.1038/sj. onc.1208822)

50 Thomas RK, Baker AC, Debiasi RM, Winckler W, Laframboise T, Lin WM, Wang M, Feng W, Zander T, MacConaill L et al. High-throughput oncogene mutation profiling in human cancer. Nature Genetics 200739 347-351. (doi:10.1038/ng1975)

51 Janku F, Wheler JJ, Westin SN, Moulder SL, Naing A, Tsimberidou AM, Fu S, Falchook GS, Hong DS, Garrido-Laguna I et al. Pi3k/akt/mtor inhibitors in patients with breast and gynecologic malignancies harboring pik3ca mutations. Journal of Clinical Oncology 201230 777-782. (doi:10.1200/JCO.2011.36.1196)

52 Oliveira C, Velho S, Moutinho C, Ferreira A, Preto A, Domingo E, Capelinha AF, Duval A, Hamelin R, Machado JC et al. Kras and braf oncogenic mutations in mss colorectal carcinoma progression. Oncogene 200726 158-163. (doi:10.1038/sj.onc.1209758)

53 Guerra A, Zeppa P, Bifulco M \& Vitale M. Concomitant brafv600e mutation and ret/ptc rearrangement is a frequent occurrence in papillary thyroid carcinoma. Thyroid 201424 254-259. (doi:10.1089/ thy.2013.0235)

54 Henderson YC, Shellenberger TD, Williams MD, El-Naggar AK, Fredrick MJ, Cieply KM \& Clayman GL. High rate of braf and ret/ptc dual mutations associated with recurrent papillary thyroid carcinoma. Clinical Cancer Research 200915 485-491. (doi:10.1158/1078-0432. CCR-08-0933)

55 Zou M, Baitei EY, Alzahrani AS, BinHumaid FS, Alkhafaji D, Al-Rijjal RA, Meyer BF \& Shi Y. Concomitant ras, ret/ptc, or braf mutations in advanced stage of papillary thyroid carcinoma. Thyroid 201424 1256-1266. (doi:10.1089/thy.2013.0610)

56 Zhu Z, Ciampi R, Nikiforova MN, Gandhi M \& Nikiforov YE. Prevalence of ret/ptc rearrangements in thyroid papillary carcinomas: effects of the detection methods and genetic heterogeneity. Journal of Clinical Endocrinology and Metabolism 200691 3603-3610. (doi:10.1210/ jc.2006-1006)

57 Guerra A, Sapio MR, Marotta V, Campanile E, Rossi S, Forno I, Fugazzola L, Budillon A, Moccia T, Fenzi G et al. The primary occurrence of braf(v600e) is a rare clonal event in papillary thyroid carcinoma. Journal of Clinical Endocrinology and Metabolism 201297 517-524. (doi:10.1210/jc.2011-0618)

58 Pellegriti G, Scollo C, Lumera G, Regalbuto C, Vigneri R \& Belfiore A. Clinical behavior and outcome of papillary thyroid cancers smaller than $1.5 \mathrm{~cm}$ in diameter: Study of 299 cases. Journal of Clinical Endocrinology and Metabolism 200489 3713-3720. (doi:10.1210/ jc.2003-031982)
59 Wartofsky L. Should patients with papillary microcarcinoma undergo radioiodine ablation? Endocrine 201344 278-279. (doi:10.1007/ s12020-013-0010-3)

60 Lee KJ, Cho YJ, Kim SJ, Lee SC, Kim JG, Ahn CJ \& Lee DH. Analysis of the clinicopathologic features of papillary thyroid microcarcinoma based on 7-mm tumor size. World Journal of Surgery 201135 318-323. (doi:10.1007/s00268-010-0886-5)

61 Chakravarty D, Santos E, Ryder M, Knauf JA, Liao XH, West BL, Bollag G, Kolesnick R, Thin TH, Rosen N et al. Small-molecule mapk inhibitors restore radioiodine incorporation in mouse thyroid cancers with conditional braf activation. Journal of Clinical Investigation 2011 121 4700-4711. (doi:10.1172/JCI46382)

62 Kim HJ, Kim NK, Choi JH, Kim SW, Jin SM, Suh S, Bae JC, Min YK \& Chung JH. Radioactive iodine ablation does not prevent recurrences in patients with papillary thyroid microcarcinoma. Clinical Endocrinology 201378 614-620. (doi:10.1111/cen.12034)

63 Romei C \& Elisei R. Ret/ptc translocations and clinico-pathological features in human papillary thyroid carcinoma. Frontiers in Endocrinology 20123 54. (doi:10.3389/fendo.2012.00054)

64 Durante C, Puxeddu E, Ferretti E, Morisi R, Moretti S, Bruno R, Barbi F, Avenia N, Scipioni A, Verrienti A et al. Braf mutations in papillary thyroid carcinomas inhibit genes involved in iodine metabolism. Journal of Clinical Endocrinology and Metabolism 200792 2840-2843. (doi:10.1210/jc.2006-2707)

65 Charles RP, Iezza G, Amendola E, Dankort D \& McMahon M. Mutationally activated braf(v600e) elicits papillary thyroid cancer in the adult mouse. Cancer Research 201171 3863-3871. (doi:10.1158/ 0008-5472.CAN-10-4463)

66 Franco AT, Malaguarnera R, Refetoff S, Liao XH, Lundsmith E, Kimura S, Pritchard C, Marais R, Davies TF, Weinstein LS et al. Thyrotrophin receptor signaling dependence of braf-induced thyroid tumor initiation in mice. PNAS 2011108 1615-1620. (doi:10.1073/pnas. 1015557108)

67 Knauf JA, Ma X, Smith EP, Zhang L, Mitsutake N, Liao XH, Refetoff S, Nikiforov YE \& Fagin JA. Targeted expression of brafv600e in thyroid cells of transgenic mice results in papillary thyroid cancers that undergo dedifferentiation. Cancer Research 200565 4238-4245. (doi:10.1158/0008-5472.CAN-05-0047)

68 Nikiforova MN, Ciampi R, Salvatore G, Santoro M, Gandhi M, Knauf JA, Thomas GA, Jeremiah S, Bogdanova TI, Tronko MD et al. Low prevalence of braf mutations in radiation-induced thyroid tumors in contrast to sporadic papillary carcinomas. Cancer Letters 2004209 1-6. (doi:10.1016/j.canlet.2003.12.004)

69 Domingues R, Mendonca E, Sobrinho L \& Bugalho MJ. Searching for ret/ptc rearrangements and braf v599e mutation in thyroid aspirates might contribute to establish a preoperative diagnosis of papillary thyroid carcinoma. Cytopathology 2005 16 27-31. (doi:10.1111/j.13652303.2004.00223.x)

70 Puxeddu E, Moretti S, Elisei R, Romei C, Pascucci R, Martinelli M, Marino C, Avenia N, Rossi ED, Fadda G et al. Braf(v599e) mutation is the leading genetic event in adult sporadic papillary thyroid carcinomas. Journal of Clinical Endocrinology and Metabolism 200489 2414-2420. (doi:10.1210/jc.2003-031425)

71 Di Cristofaro J, Marcy M, Vasko V, Sebag F, Fakhry N, WynfordThomas D \& De Micco C. Molecular genetic study comparing follicular variant versus classic papillary thyroid carcinomas: association of n-ras mutation in codon 61 with follicular variant. Human Pathology 200637 824-830. (doi:10.1016/j.humpath.2006.01.030)

72 Di Cristofaro J, Silvy M, Lanteaume A, Marcy M, Carayon P \& De Micco C. Expression of tpo mrna in thyroid tumors: quantitative pcr analysis and correlation with alterations of ret, braf, ras and pax8 genes. Endocrine-Related Cancer 200613 485-495. (doi:10.1677/erc.1.01164)

73 Wang YL, Wang JC, Wu Y, Zhang L, Huang CP, Shen Q, Zhu YX, Li DS \& Ji QH. Incidentally simultaneous occurrence of ret/ptc, h4-pten and braf mutation in papillary thyroid carcinoma. Cancer Letters 2008263 44-52. (doi:10.1016/j.canlet.2007.12.018) 
74 Muzza M, Degl'Innocenti D, Colombo C, Perrino M, Ravasi E, Rossi S, Cirello V, Beck-Peccoz P, Borrello MG \& Fugazzola L. The tight relationship between papillary thyroid cancer, autoimmunity and inflammation: clinical and molecular studies. Clinical Endocrinology 201072 702-708. (doi:10.1111/j.1365-2265.2009.03699.x)

75 Stanojevic B, Dzodic R, Saenko V, Milovanovic Z, Pupic G, Zivkovic O, Markovic I, Djurisic I, Buta M, Dimitrijevic B et al. Mutational and clinico-pathological analysis of papillary thyroid carcinoma in serbia. Endocrine Journal 201158 381-393. (doi:10.1507/endocrj.K11E-054) 76 Dinets A, Hulchiy M, Sofiadis A, Ghaderi M, Hoog A, Larsson C \& Zedenius J. Clinical, genetic, and immunohistochemical characterization of 70 ukrainian adult cases with post-chornobyl papillary thyroid carcinoma. European Journal of Endocrinology 2012166 1049-1060. (doi:10.1530/EJE-12-0144)

Received 3 March 2015

Revised version received 22 June 2015

Accepted 20 July 2015 